\title{
The UK Energy Research Centre Meeting Place: a transferable model for international energy research collaboration and networking?
}

\author{
S. Keay-Bright \\ University of Oxford, UK
}

\begin{abstract}
The Meeting Place was set up in October 2004 - under the auspices of the UK Energy Research Centre as part of a cross Research Council funded initiative to provide the UK energy research community with a resource that would enable UK researchers of different disciplines to collaborate with other researchers and stakeholders based in the UK and overseas.

This paper aims to inform the energy research community of what the Meeting Place is and does, and the lessons learnt so far. The paper explains the evolution of the Meeting Place model, the factors that have shaped its current form and discusses possible future directions. The possibility of transferring this model to other countries or sectors is also discussed. The paper draws on experience from running the Meeting Place as well as feedback from the energy community. The set up of the Meeting Place is also compared with other highprofile international residential research collaboration centres such as the Isaac Newton Centre and the Bellagio Institute.

The Meeting Place model is able to meet the widely varying needs of the energy community through its activity management and development service. This model provides for a flexible approach in both the format and location of activities which is effective in terms of output as well as costs. The intellectual input of the Meeting Place team into the development process, the team's expertise in managing and arranging activities, as well as the provision of financial and administrative support, helps deliver a professional and productive output that adds value and which members of the energy research community could not have achieved alone. While there are opportunities for further improvement and development, this model should be easily transferable to other countries or sectors.
\end{abstract}

Keywords: UKERC Meeting Place, international energy research collaboration, stakeholder engagement, networking, dialogue, interdisciplinary. 


\section{Introduction}

The Meeting Place was set up in October 2004 - under the auspices of the UK Energy Research Centre (UKERC) as part of a Government funded initiative - to provide the UK energy research community with a resource that would enable UK and international researchers of different disciplines to collaborate with one another. The Meeting Place is currently managed by the Environmental Change Institute of Oxford University, based in the UK.

The current model of the Meeting Place:

- is dedicated to furthering research and policy agendas through interdisciplinary problem-solving events, debates, networking activities, research collaborations and interactions with international visitors;

- brings together people from many different disciplines and professions that would not normally meet or work together;

- facilitates dialogue and multi-stakeholder engagement;

- pursues activities based on proposals received from members of the energy research community; and

- $\quad$ provides a management and development service for activities (rather than a permanent physical location as the title 'Meeting Place' might suggest), delivering intellectual input and flexibility in the location and format of activities.

This paper considers how the current model of the Meeting Place meets the needs of the UK energy research community. The paper also explains the evolution of the Meeting Place model, the factors that have shaped its current form and highlights possible future directions. The possibility of transferring this model to other countries or sectors is discussed. The paper draws on experience from running the Meeting Place, feedback from the energy community and comparison with other high-profile international residential research collaboration centres.

\section{What is the UK Energy Research Centre?}

UKERC is a central part of the UK's $£ 28$ million cross-Research Councils programme "Towards a Sustainable Energy Economy (TSEC)" and is funded by the Government through three Research Councils: the Engineering and Physical Sciences Research Council (EPSRC), the Natural Environment Research Council (NERC) and the Economic and Social Research Council (ESRC). The Centre was established following a recommendation made by the UK Government's Chief Scientific Advisor's "Energy Research Review Group - 2002 report”. Broadly, the report recommended setting up a new Energy Research Centre to:

- $\quad$ bring together government, industry and academia;

- be a networking centre to co-ordinate UK research, facilitate industry collaboration and promote UK participation in international projects; 
- be a centre of excellence in its own right; and

- help maximise returns from research investment and leverage private sector funds.

As an international gateway and networking hub for UKERC, the Meeting Place significantly contributes to UKERC's aims to enable multi-stakeholder dialogue and to facilitate collaboration. The Meeting Place also provides a major contribution to UKERC's facilitation of the National Energy Research Network (NERN), an umbrella network incorporating UK energy researchers of all disciplines.

In addition to the Meeting Place function, UKERC has its own research programme and a Technology and Policy Assessment function (TPA) which draws on existing energy research to develop accessible reports relevant to policymakers and other stakeholders. UKERC also has the remit to set up a webbased Energy Research Atlas to provide an authoritative account of research capabilities and unsolved research problems across the energy domain. UKERC functions and activities, including the Meeting Place, are overseen by the Research Director and Executive Director, both based at UKERC's headquarters in London.

\section{Original concept and objectives}

The Government-funded Research Councils awarded the Meeting Place a budget of just over $£ 1 \mathrm{~m}$ spread over $4 \frac{1}{2}$ years. Initially it was proposed to designate a single location as the physical focus for UKERC's networking activities. It was intended that this would provide a focused, convivial environment for academic debate and thought where members of the UK energy community could engage with each other and with overseas visitors.

The University of Oxford agreed, on winning the award, to provide and cover the costs of desk space for Meeting Place staff and for 6 to 10 visitors, a dedicated small meeting room and shared access to departmental (Oxford University Centre for the Environment (OUCE)) facilities and human resources. Shared human resources cover finance, personnel and reception services. The funds awarded by the Research Councils are dedicated to Meeting Place staff salaries and expenditure on activities, including costs associated with meeting venues, catering and travel.

The main objectives of the Meeting Place are to:

- learn from and contribute to the development of energy research within the international community;

- $\quad$ stimulate inter-disciplinary debate;

- $\quad$ provide a forum for collaborative projects addressing key issues;

- develop new synergies between different strands of energy research; and

- build-up the strengths of the research community. 


\section{Evolution of the UKERC Meeting Place model}

\subsection{Initial ideas}

The original concept envisaged that the Meeting Place would meet its objectives through delivering events and hosting visitors. It was not clear what type of format these events and visits might take largely because the needs of the UK energy research community and the scale and nature of demand were relatively uncertain and could only be better defined with experience. Thus, in the early days the future work programme for the Meeting Place was difficult to predict as were the implications for the balance of human resources and expenditure on activities such as events and visits. As the idea of the "Meeting Place" was new to the research community it was intended that the first two years would involve experimenting with several ways of working and these would be evaluated after the first two years of operation.

At the time of its inception in 2004, several possible formats were mooted for the way in which the Meeting Place might operate. The Meeting Place was open to adopting any number and type of format as appropriate. These included:

- $\quad$ Format A - Hosting a small group (a temporary, interdisciplinary group 'think-tank') of international and UK experts at the Meeting Place for an extended period of time (weeks/months) to focus on a specific issue.

- Format B - Hosting individual practitioners and policymakers in the Meeting Place for short career breaks or sabbaticals for several weeks or months.

- Format $\mathrm{C}-\mathrm{A}$ project involving a series of meetings with a clear agenda and structure. Research and thinking would take place between meetings. Meetings would last for say two to three days and could involve anything from 5-80 people, depending on the precise rationale for the event.

- Format D - Short events, such a workshops, seminars or conferences, with a meeting report as a key output.

\subsection{Identifying the needs and demand of the energy research community}

It was expected that the Meeting Place would achieve its objectives through delivering activities which would enable high-level researchers in the energy domain to remove themselves from their normal work environment and focus their minds on pressing complex interdisciplinary problems. It was initially thought that formats $\mathrm{A}$ and $\mathrm{B}$ would contribute significantly to this aim. However, it has proved difficult to bring together international experts for more than a few days at a time. This is due to various reasons, but particularly due to the fact that the Meeting Place is not able to pay salaries, commissions or fees. Institutions employing experts could be understandably reluctant to support extended visits of more than a few days, depending on the direct relevance of the visit or meeting to the tasks that the employee is under contract to deliver for 
his/her institution. It is the case that most researchers are extremely busy and many prefer not to be away from their families or home for very long. Instead academics often favour working at their own desk, working offline and communicating by email or through PC-based video-conferencing which the Meeting Place supports and can facilitate. It is very difficult to coordinate diaries for any length of time. For the reasons above, formats $\mathrm{C}$ and $\mathrm{D}$ have been most popular to date.

The Meeting Place employs meeting formats appropriate to the needs of its users. To date, it has delivered activities covering the formats A-D outlined above in section 4.1, and variations of these formats. See Table 1 below for examples. The Meeting Place intends to continue to experiment with new formats to meet users' needs as effectively as possible and to deliver the required outputs.

\subsection{Research-focused activities}

The Meeting Place has hosted numerous 'research-focused activities' which often involve two to three day workshops for groups of experts, perhaps as oneoff meetings or as a series of meetings - similar to format $\mathrm{C}$ outlined above. This type of activity is research-focused and enables researchers from different disciplines and institutions, both UK and international, to work together in a supportive environment to develop a specific aspect of sustainable energy research and frequently to explore new concepts or ideas. Central to this type of activity is the fact that the participants work together away from their normal institutions for a period of time and produce a useful research-related output.

A clear demand for such research-focused activities has emerged from the energy research community. These activities, if effectively planned and facilitated, can produce useful research outputs such as a peer-reviewed special issue of a journal, book or technology roadmap. Much work is undertaken offline before, during and after the meeting(s).

The Meeting Place has hosted several international technology roadmapping workshops which have contributed to the development of research roadmaps for bio-energy, photovoltaics, carbon capture and storage and marine renewable energy. Another example of a research-focused collaboration activity is the "Innovation and Energy Systems research focused workshop series", held in March and September 2006, in Oxford. This example is outlined in Table 1 below.

\subsection{Short events}

To date, the greatest demand for Meeting Place support has been for short oneoff workshops and seminars (format D). Feedback from participants suggests that this demand is related to the provision of:

- $\quad$ an independent, neutral forum;

- intellectual input in developing, planning and generally facilitating the meeting; 
- facilitation of dialogue and interaction during meetings or workshops;

- a professional service with respect to organisation of logistics;

- financial resources to cover the event costs; and

- access to new contacts and networks (through the Meeting Place team, the UKERC Directorate, and UKERC's National Energy Research Network database).

In addition, proposing groups/individuals are more willing and ready to commit their time to planning and delivering a short event compared with longer term visits or research-focused activities because of other competing workrelated commitments.

Several Meeting Place short events have been co-sponsored by other institutes. Institutes have chosen to co-sponsor for a number of reasons, including many of those listed above.

Table 1: $\quad$ Some examples of Meeting Place activities.

\section{Short event : workshop}

Climate Change Metrics 2-day workshop, November 2004, Oxford. This event brought together experts of many different professions and disciplines to debate the merits of different climate change metrics options to enable inclusion of other sectors, in particular aviation, and greenhouse gases in the EU emissions trading scheme (EU ETS). This workshop informed stakeholders - involved in the consultation process relating to the inclusion of aviation in the EU ETS - of the science and complexity of the problems at hand. The workshop was particularly useful to consultants providing advice to the European Commission on this subject.

\section{Research-focused activity: series of two 2-day workshops}

Innovation and Energy Systems research focused workshop series, MarchSeptember 2006, Oxford. This two part intensive research-focused activity brought together leading representatives from economic, institutional and management perspectives to describe their respective approaches to innovation in energy systems, share knowledge and insights, and come to a greater degree of common understanding. The output of this series of workshops is a peer-reviewed book.

\subsection{Longer term international visitors}

For the reasons previously explained, there has been much less demand for hosting longer term international visitors (formats A and B) compared with short events and research-focused activities (formats $\mathrm{C}$ and $\mathrm{D}$ ). Experience has demonstrated that overseas researchers coming to the UK with the aim of interacting with UK researchers need to be located at an institution which shares their research interests. 
People able to undertake extended stays are more likely to be students, retired academics or experts taking a sabbatical or career break; because these people are less likely to be employed, they are more likely to need funding to support basic living costs. The Meeting Place can not fund salaries or fees but it can advise long-stay applicants of available funding sources for basic living costs and can contribute to the cost of accommodation, catering and travel.

With a primary objective to facilitate interaction between UK and international researchers, the Meeting Place now offers to assist overseas researchers wanting to visit a UK-based institution and also supports UK-based institutions wishing to host international visitors. Costs to be covered by the Meeting Place are assessed on a case by case basis depending on factors such as the expected outcomes of the visit. Desk space is available in Oxford for researchers without a host institution. However, these researchers are still expected to interact with the UK energy community in some way.

The Meeting Place encourages visitors to produce peer-reviewed research outputs where appropriate and requires each visitor to prepare a brief report following their stay outlining the activities undertaken and outputs achieved.

\subsection{Selection of proposals}

Ideas for Meeting Place activities come from members of the energy research community, as well as the UKERC Research and Executive Directors and the UKERC Co-Directors. UKERC Directors are well placed to find users, individuals or institutes, who could benefit from the support of the Meeting Place as through their work for UKERC they are required to promote networking. The Directors therefore have a good overview of energy research activities across the UK and overseas and are in direct and regular contact with many of the key players in academic, business and policy circles.

The Meeting Place applies basic selection criteria to proposals. Selection depends on the quality of the proposal, its importance to the UK energy community, the ability of the applicant to deliver and its fitting with the Meeting Place objectives. The Meeting Place strongly supports proposals which encourage interdisciplinary working and international collaboration.

Proposals are assessed by the UKERC Meeting Place Co-Managers and Director, the UKERC Research Director and other experts as appropriate.

\subsection{Infrastructure and operation}

\subsubsection{Cost effective use of facilities}

The Meeting Place has dedicated desk space for visitors and a small boardroom, within OUCE, as well as shared access to OUCE meeting facilities, including an auditorium, smaller lecture rooms and small breakout rooms. Departmental students and staff have priority during term time. When the departmental facilities are not available or not ideally suited to the purposes of the meeting, the Meeting Place hires facilities elsewhere. Most activities to date have been hosted at venues outside the department. 
As Oxford is a central location within the UK, with good transport links to surrounding regions, the Meeting Place regularly makes use of the Oxford colleges. As the traditional entrée to the University and its academics, in both intellectual and social terms, the colleges are able to provide very pleasant and suitable residential meeting facilities. Many colleges have purpose-built conference facilities and employ a conference co-ordinator or team. Unlike the OUCE department, most colleges can provide in-house catering services, including evening meals. Many of the colleges also have delightful gardens which provide fresh air, thinking space, exercise and restful breaks. Colleges are able to hire out meeting facilities all year round and can provide en-suite accommodation during vacation time. The Meeting Place has also hired facilities in other geographic locations, often favouring non-commercial institutes rather than hotels as they generally offer better value for money.

Since the formats of Meeting Place activities have varied considerably from large conferences, to large open space workshops, medium-sized workshops with breakout room requirements to small seminars or meetings, flexibility in the type of facilities used is essential. As the Meeting Place is open to any format as well as any geographic location, hiring facilities allows for greater flexibility. Even if the Meeting Place did have it own dedicated facilities, it is unlikely that they would fully meet the needs of the Meeting Place and with a current average of two activities a month, the facilities would be under-used most of the time. So far, sharing and hiring of facilities has been the most cost-effective option and this approach also offers flexibility, enabling the Meeting Place to meet the needs of its users.

Residential research institutes such as the Isaac Newton Centre (UK), the Bellagio Study and Conference Center (Italy) and the Santa Fe Institute (USA) have dedicated facilities which house meeting space, catering and accommodation under one roof. To make such a set-up possible, major funds are needed to purchase or rent the facilities. These institutes either own their facilities or use them rent/lease-free and have operating budgets on a much larger scale compared with the Meeting Place.

\subsubsection{Equipment and audio/video-conferencing}

Since its inception, the Meeting Place has been committed to the use of audio/video-conferencing to facilitate more effective communication across the energy research community and also to reduce the community's carbon footprint. After considering numerous options, it was concluded that PC-based audio/video conferencing would be the most appropriate solution for the Meeting Place. The only additional hardware required is a headset and webcam (assuming users already have a personal computer). As the Meeting Place hosts meetings in many different venues it would not make sense to purchase bulky hardware intended for permanent installation in a meeting room. A department of the University of Oxford has purchased several licences for Macromedia Breeze conferencing software. For a small fee, the Meeting Place has access to this software. The Meeting Place regularly uses this facility for activity development, planning meetings and international meetings. 


\subsubsection{Reliance on a small team}

The Meeting Place started out with a director (10\% full time equivalent, FTE), a manager (100\% FTE) and an events assistant (50\% FTE). The team has since expanded twice, from 1.6 FTE to $3.1 \mathrm{FTE}$; the first expansion bringing in a full time administrative assistant and the second resulting in an additional manager.

The Co-Managers develop the activities and are responsible for their delivery. They both have excellent academic backgrounds and experience in the field of energy. They are also both trained facilitators. The events assistant handles the logistics and administration. The Meeting Place Director (10\% FTE) represents the Meeting Place within the University of Oxford and externally, and inputs into its strategic direction. The UKERC Research Director gives guidance and support on research aspects of Meeting Place activities. The UKERC Executive Director is ultimately responsible for all UKERC activities and functions, including the Meeting Place.

It was always the intention that the Meeting Place team would provide more than simply an events management service. Having said that, event organisation is a very important role of the Meeting Place. The amount of effort and time that is put into organising an activity is often severely underestimated and not fully appreciated. With staff time fully allocated to delivering activities, the Meeting Place is able to provide a professional service with attention to detail that ensures peace of mind, allowing academics to focus on their work, and delivers smoothrunning productive events. The Co-Managers design and facilitate the workshops or meetings. This latter aspect is not provided by other residential research institutes or initiatives such as the Dahlem Conferences (Germany), the Isaac Newton Centre, the Bellagio Study and Conference Center or the Santa Fe Institute. Thorough planning and effective meeting/process design are very important elements that are essential for a successful and productive activity. Few academics are adequately resourced to deal professionally with logistics, meeting design or facilitation. Previous users of the Meeting Place have expressed much appreciation for the professionalism and expertise of the Meeting Place.

\subsubsection{Minimising the carbon footprint of the Meeting Place}

As the content of all meetings relates to sustainable energy systems, the Meeting Place endeavours to minimise its carbon footprint as far as possible. The Meeting Place offsets the carbon emissions of any travel that it purchases for participants. The Meeting Place also has a food policy that it encourages caterers to adopt. The food policy sets out guidelines which promote sustainable low carbon food consumption.

\section{How successful is the UKERC Meeting Place?}

In its first two years of operation, some 1500 people from 35 different countries, attended a total of 40 Meeting Place meetings, workshops, conferences or seminars. The number of activities has generally grown each quarter and the Meeting Place team has expanded to keep pace. The Meeting Place currently 
hosts an average of two activities per month. The increasing demand and positive feedback from participants indicates that the Meeting Place is a useful and unique resource for the energy research community. The Meeting Place is now a well respected and recognised brand with more to be done in raising its profile within the UK and abroad.

The Meeting Place produces a number of written outputs. There are reporting requirements for Meeting Place activities and these depend on the type of activity. Workshops and seminars require a meeting report while international visitors are required to write a summary of activities, including visits undertaken and contacts made, research papers published etc. Any material relating to a Meeting Place activity is posted on the UKERC website and is a useful and everexpanding resource for the energy research community e.g. workshop presentations; workshop reports; peer-reviewed publications; contact lists.

Meeting Place activities result in various outputs aside from written reports and peer-reviewed publications. Such outputs might include networking and establishing contacts, setting up of research collaborations or development of policy and research agendas. These outputs are usually difficult to identify but the Meeting Place is taking steps to evaluate the effectiveness of activities as fully as possible.

\section{Discussion and conclusions}

The UKERC Meeting Place was set up by the UK Research Councils to facilitate interaction between UK and international energy researchers. The Meeting Place is achieving this through delivery of short events and research-focused activities and through facilitating visits of international researchers. The Meeting Place is open to undertaking any format of activity in order to most effectively meet the needs of its users. Short events and research-focused activities involving short residential workshops have so far proved to be more popular than longer term visits or collaborations. This is for a number of reasons but largely because participants are usually unable to commit to long periods of time away from the office, the difficulty in coordinating the diaries of busy academics and stakeholders and because the Meeting Place is not able to fund commissions, salaries or fees.

Although small, the Meeting Place team is able to ensure that activities add value and that they are professionally delivered as the team is fully responsible for the collaborative process from start to finish, including developing, facilitating and delivering the activities; this aspect is often missing in other residential research models and is one of the unique features of the Meeting Place. This feature is an easily transferable aspect of the Meeting Place model.

The Meeting Place model has proved that it is possible to meet the varied needs of the energy research community without dedicated meeting facilities and on a relatively small budget. Shared access to departmental facilities and human resources coupled with the capability to hire facilities as required is a costeffective way to operate and allows the Meeting Place much necessary flexibility 
in selection of appropriate venues for activities. It should be possible to replicate this set-up in other countries.

The Oxford Colleges are a major asset to the Meeting Place. This collegiate arrangement is not generally replicated in other countries. However, this should not be an impediment to the transfer of the Meeting Place model to other countries or sectors as most large cities offer a wealth of conference facilities which are available for hire.

For the reasons set out above, it is the opinion of the author that the Meeting Place model could be transferred as a stand-alone model (without the other elements of the UKERC) to countries where international collaboration and interdisciplinary working needs to be facilitated. The model might also be transferable to other sectors which have needs similar to the energy research community. It has not been within the scope of this paper to assess the transferability of all elements of the UKERC to other countries. However, the research expertise, network knowledge and communications support (including the UKERC website) provided by UKERC's headquarters are particularly useful to the operation of the Meeting Place.

\section{Future directions}

Much of the success of the Meeting Place to date has been due to its flexible approach and ability to adapt to meet the needs of its users and to satisfy the requirements of the Research Councils. The Meeting Place will continue with this approach, seeking the optimum balance between expenditure on human resources and activities. The Meeting Place will continue to seek improvements through gathering feedback from its users, funders and the UKERC Advisory Board.

In the future, there may be the possibility for leveraging in funds from other sources, particularly industry, for increased co-sponsorship of activities or for contributions to core funding. At some point in the future, the volume of Meeting Place activities may reach a critical point whereby the Meeting Place could benefit from dedicated facilities. However, the set up or purchase of a purpose-built building would require a very large injection of capital. 